\title{
NOTCH Family Gene Mutation
}

National Cancer Institute

\section{Source}

National Cancer Institute. NOTCH Family Gene Mutation. NCI Thesaurus. Code C136644.

A change in the nucleotide sequence of a gene that is a member of the NOTCH gene family. 